\title{
Therapeutic efficacy of pentoxifylline on proteinuria and renal progression: an update
}

\author{
Yung-Ming Chen ${ }^{1 *}$, Wen-Chih Chiang ${ }^{1}$, Shuei-Liong Lin ${ }^{1,2^{*}}$ (D) and Tun-Jun Tsai ${ }^{1}$
}

\begin{abstract}
Blood pressure control with renin-angiotensin system (RAS) blockade has remained the gold standard for treating patients with proteinuric chronic kidney disease (CKD) up to date. Nevertheless, RAS blockade slows but does not halt the progression of kidney disease, thus highlighting the need to search for additional therapeutic approaches. The nonselective phosphodiesterase (PDE) inhibitor pentoxifylline (PTX) is an old drug that exhibits prominent anti-inflammatory, anti-proliferative and anti-fibrotic activities both in vitro and in vivo. Studies in human subjects have shown that PTX monotherapy decreases urinary protein excretion, and add-on therapy of PTX to background RAS blockade additively reduces proteinuria in patients with CKD of various etiology. More recent studies find that PTX combined with RAS blockade delays the decline of glomerular filtration rate in diabetic patients with mild to moderate CKD, and reduces the risk of end-stage renal disease in diabetic and non-diabetic patients in late stage of CKD with high proteinuria levels. In this review, we update the clinical trial results of PTX as monotherapy, or in conjunction or in comparison with RAS blockade on patients with proteinuria and CKD, and propose a mechanistic scheme explaining the renoprotective activities of this drug.
\end{abstract}

Keywords: CKD, ESRD, Pentoxifylline, Proteinuria, Renin-angiotensin system

\section{Background}

Current practice guidelines recommend blood pressure control with inhibitors of the renin-angiotensin system (RAS) as the gold standard therapy for patients with proteinuric chronic kidney disease (CKD) [1-3]. Blocking the RAS by either angiotensin converting enzyme inhibitors (ACEIs) or angiotensin receptor blockers (ARBs) slows but does not stop the progression of kidney disease [4]. This highlights the need to search for additional therapeutic approaches beyond RAS blockade [5]. However, new drug development for kidney diseases has been limited, and except for some glucose-lowering drugs [6], no novel agents targeting renal progression have been marketed since the new millennium $[7,8]$. Recently, the cyclic nucleotide phosphodiesterase (PDE) has emerged as a promising target for pharmacological intervention against CKD progression

\footnotetext{
* Correspondence: chenym@ntuh.gov.tw; linsl@ntu.edu.tw

${ }^{1}$ Renal Division, Department of Medicine, National Taiwan University Hospital, College of Medicine, National Taiwan University, No. 7, Chung-Shan South Road, Taipei, Taiwan

Full list of author information is available at the end of the article
}

$[9,10]$. The nonselective PDE inhibitor pentoxifylline (PTX) is an old drug that exhibits prominent antiinflammatory, anti-proliferative and anti-fibrotic activities both in vitro and in vivo $[11,12]$. In addition to its classic indication for intermittent claudication [13-15], PTX has been used off-label to treat a variety of inflammatory and/ or fibrotic disorders, including that arise from the kidney [16-21]. To understand further the impact of PTX therapy on renal diseases since our previous review [22, 23], we conducted a search of the literature using the PubMed, EMBASE, Cochrane Central Register of Controlled Trials, and Cochrane Database of Systematic Reviews. Key words used as search terms were "pentoxifylline", "diabetic proteinuria", "non-diabetic proteinuria", and "renal progression", "chronic kidney disease", "meta-analysis", and "systematic review". Results were limited to studies in human subjects published in the English language after December 2004, and those studies using PTX with or without RAS blockade. Studies focused on the effects of PTX on drug induced nephrotoxicity were excluded. Using the search methods described above, 27 relevant 
articles were retrieved and evaluated. The populations studied were patients with CKD across all 5 stages. We stratify these studies based on the treatment intervals and primary endpoints, i.e., short-term effects ( $\leqq 6$ months), either monotherapy or add-on existing RAS blockade, on proteinuria; longer term ( $\geqq 12$ months) add-on therapy to background RAS blockers on renal function. Of the 27 studies, 4 analyzed the effect of PTX on non-diabetic proteinuria, 13 assessed the effect of PTX on diabetic proteinuria, including 3 meta-analyses and systematic reviews, and 10 evaluated the changes in estimated glomerular filtration rate (eGFR), including 4 randomized clinical trials, 3 meta-analyses and systematic reviews and 3 cohort observational studies. In this narrative review, we update the clinical trial results of PTX as monotherapy, or in conjunction or in comparison with RAS blockade, on patients with proteinuria and CKD, and propose a mechanistic scheme based on our prior works to account for the renoprotective activities of this drug.

\section{Main text \\ Efficacy of PTX on non-diabetic proteinuria}

Table 1 shows representative studies examining the efficacy of PTX on non-diabetic patients with proteinuria. Chen et al. [24]. reported that treatment with PTX at a dose of $800 \mathrm{mg}$ daily for 6 months decreased proteinuria from averaging 2.82 to $1.79 \mathrm{~g} / \mathrm{g}$ Creatinine (g/gCr) in 17 primary glomerulonephritic patients. The efficacy was associated with reduced urinary monocyte chemoattractant protein (MCP)-1 excretion, proposing a mechanistic basis for PTX in non-diabetic patients with proteinuria. Then, in a placebo-controlled, cross-over study, Renke et al. [25] found PTX at a dose of $1200 \mathrm{mg}$ daily reduced proteinuria by $26 \%$ in comparison with placebo in 22 non-diabetic patients with proteinuria between 0.4 and $4.3 \mathrm{~g} /$ day and eGFR $>30 \mathrm{~mL} / \mathrm{min} / 1.73 \mathrm{~m}^{2}$. No differences were found between crossover periods in C-reactive protein (CRP), $\alpha 1$-microglobulin, and urinary $\mathrm{N}$-acetyl-beta-d-glucosaminidase. More recently, in a double-blind, placebocontrolled trial, Badri et al. [26] observed add-on PTX to background RAS blockade at a dose of 800-1200 mg daily for 6 months additively decreased proteinuria in 18 patients with membranous nephropathy displaying urinary protein excretion $>500 \mathrm{mg} /$ day.

In addition to native kidney disease, PTX also works in the setting of transplant kidneys. An early randomized double-blind trial found that PTX at a dose of 800$1200 \mathrm{mg}$ daily ameliorated the consequences of rejection on graft survival comparing to placebo during the first 6 months after transplantation [27]. Subsequent studies revealed temporary anti-proteinuric effects of PTX in biopsy proved chronic allograft nephropathy under RAS blockade and triple immunosuppressive therapy. The graft function was stabilized in more than half of PTX-treated patients at the end of 6-month follow-up, supporting a renoprotective role of this drug for graft disease [28, 29]. Unfortunately, all the studies mentioned above suffered the caveats of small sample size, short periods of observation and bias-prone designs, which preclude drawing a firm conclusion for the efficacy of PTX on non-diabetic patients with proteinuria.

\section{Efficacy of PTX on diabetic proteinuria}

Diabetic kidney disease (DKD) or diabetic nephropathy has become the single most important primary etiology of endstage renal disease (ESRD) worldwide [30], and the pathophysiology of which has been attributed to various metabolic and hemodynamic factors [31, 32]. Not surprisingly, glycemic control and blood pressure control with RAS blockade are widely accepted as the standard therapy for people with DKD. Besides these conventional approaches, inflammatory processes induced by tumor necrosis factor (TNF) $-\alpha$ has emerged as an alternative therapeutic target for patients with DKD [33-35]. Consistent with this notion, PTX which is a known inhibitor for TNF- $\alpha[36,37]$ has been used as an anti-proteinuric agent in DKD patients [38]. Table 2 lists the representative studies assessing the efficacy of PTX on proteinuria in DKD patients. First, Aminorroaya et al. [39] and Rodríguez-Morán et al. [40] observed PTX at a dose of $400 \mathrm{mg}$ three times daily displayed anti-proteinuric effects comparable to that achieved with captopril $25 \mathrm{mg}$ three time daily in non-hypertensive patients with type 2 diabetes. These studies showed that PTX is non-inferior to ACEI for the anti-proteinuric effect, suggesting a role of PTX in the management of diabetic proteinuria. Then, in a randomized, open-label trial, Navarro et al. [41] found add-on PTX at a dose of $1200 \mathrm{mg}$ daily to background ARB for 4 months additively decreased proteinuria in patients with type 2 diabetes. This extra antiproteinuric effect of PTX was associated with reduced serum and urinary levels of TNF- $\alpha$. However, only the change of urinary TNF- $\alpha$ correlated with the change of albuminuria. Meanwhile, in another trial using doubleblind, placebo-controlled design, PTX at a dose of $1200 \mathrm{mg}$ daily for 4 months reduced both high (glomerular) and low (tubular) molecular weight urinary protein excretion in normotensive type 2 diabetes patients with microalbuminuria [42].

Later investigators consistently found that add-on PTX on top of RAS blockade led to a greater reduction of proteinuria in patients with type 2 DKD across CKD stages 1 to 3 , and the benefit of which was independent of metabolic or blood pressure control [43, 44]. Of note, PTX's anti-proteinuric activity could still be evident at a dose of $400 \mathrm{mg}$ daily on top of RAS blockade over 6 months [44]. Roozbeh et al. [45] observed a modest decrease in systolic blood pressure associated with proteinuria reduction in patients treated with PTX and captopril, compared to 


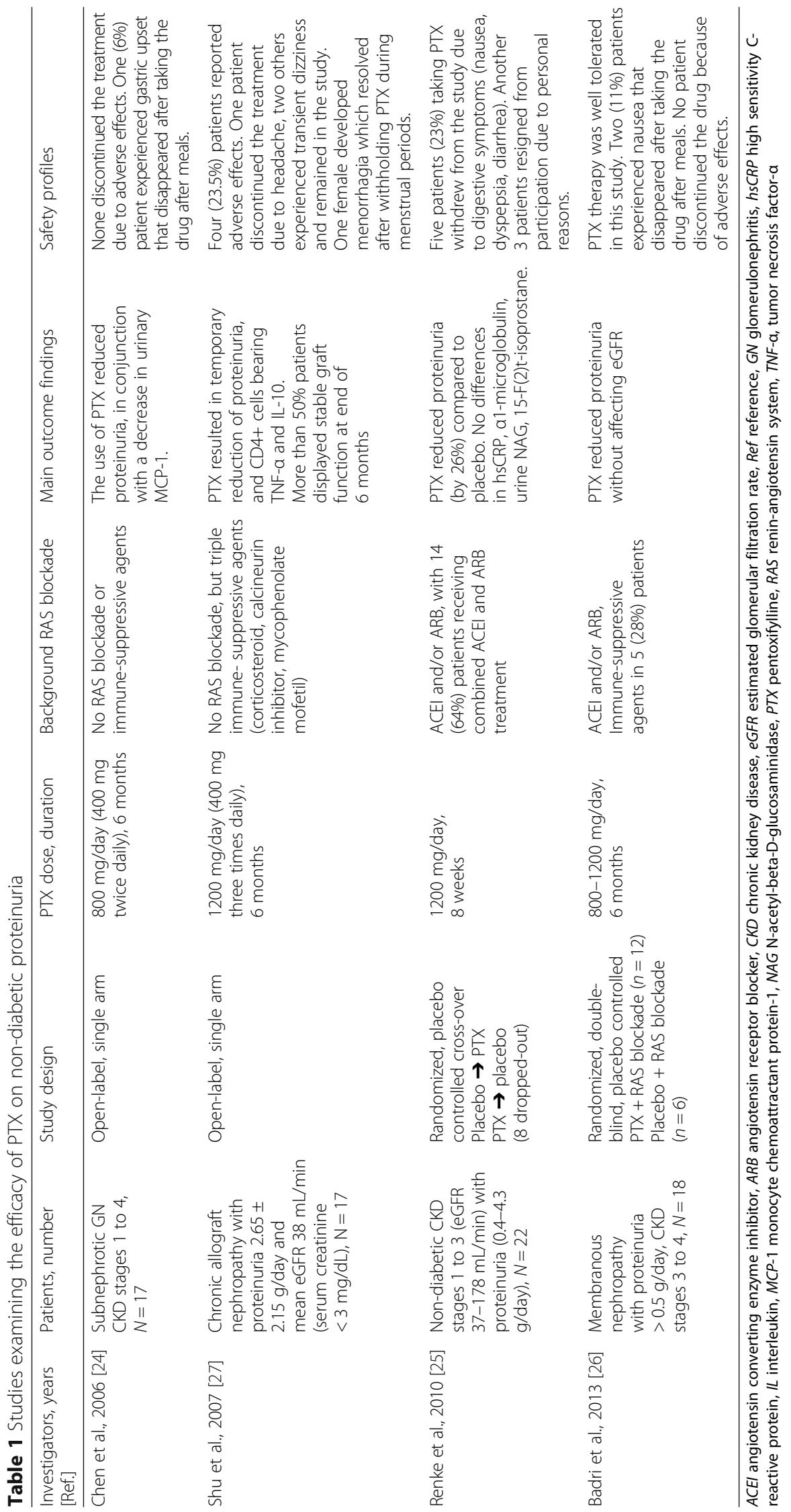




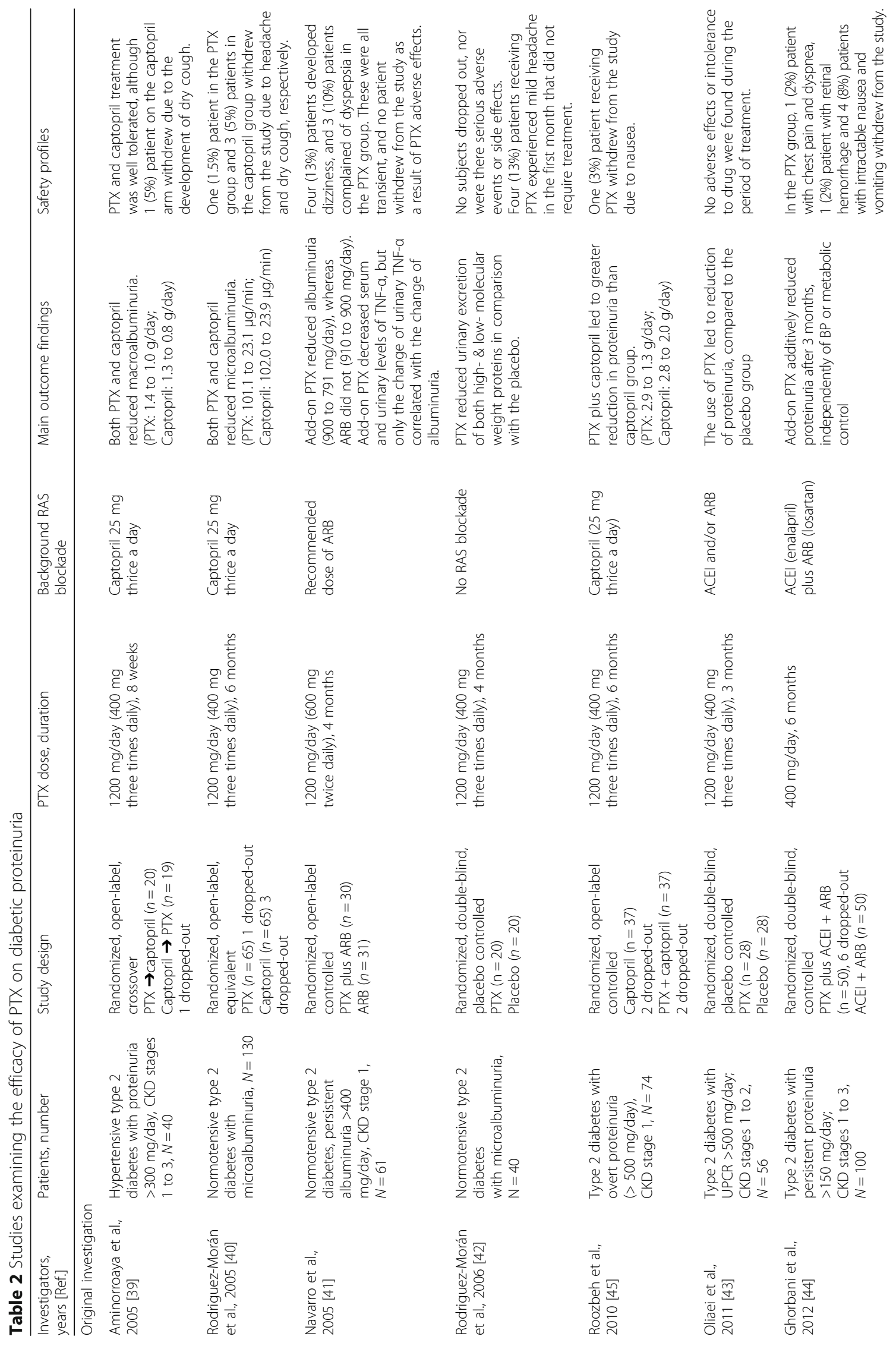




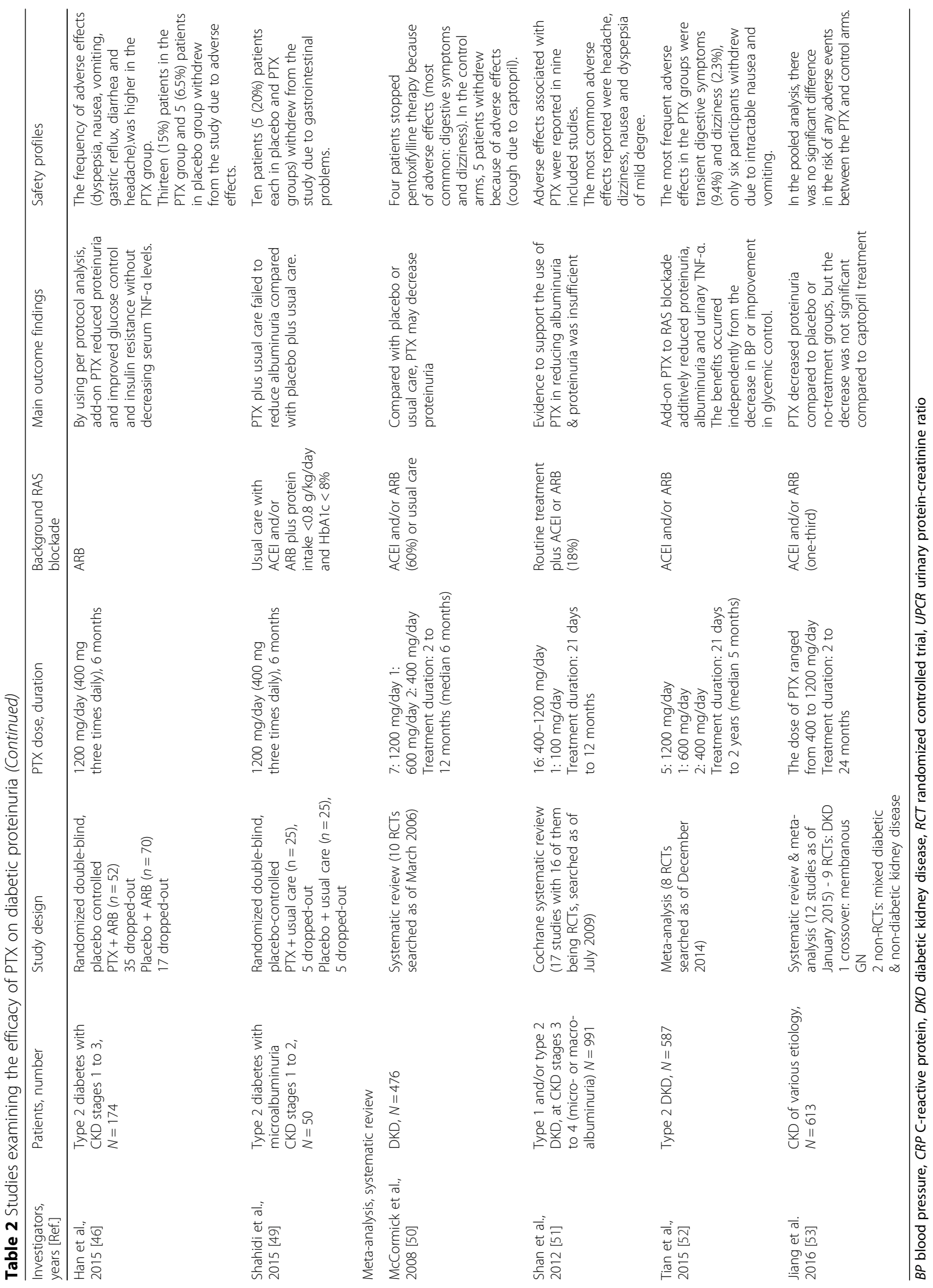


captopril monotherapy. This was the only study reporting hypotensive activity of PTX. Recently, in a randomized double-blind, placebo-controlled trial which enrolled 174 patients with type 2 DKD across CKD stages 1 to 3, Han et al. [46] showed that add-on PTX at a dose of $1200 \mathrm{mg}$ daily for 6 months reduced proteinuria and improved glucose control and insulin resistance, without decreasing serum TNF- $\alpha$ levels. The study was notable for having a high dropped-out rate in the PTX group (40.2\%) and without measuring urinary TNF- $\alpha$ levels which, compared to serum TNF- $\alpha$, would be more closely associated with the development of albuminuria [47, 48]. In a subsequent randomized, placebo-controlled trial, Shahidi et al. [49] observed no reduction of proteinuria by PTX therapy at a dose of $1200 \mathrm{mg}$ daily for 6 months in 40 type 2 DKD patients with eGFR $>60 \mathrm{~mL} / \mathrm{min} / 1.73 \mathrm{~m}^{2}$. Clearly, this study comprised patients with relatively normal renal function. They were not under uniform RAS blockade, yet receiving dietary protein restriction. These discrepancies in baseline characteristics and study designs might be linked to the lack of anti-proteinuric effects by PTX treatment.

Systematic reviews and meta-analyses have been employed to quantitatively evaluate PTX's anti-proteinuric effects in diabetic patients with microalbuminuria or overt proteinuria. The first work was by McCormick et al. [50] which included 10 randomized clinical trials and a total of 476 patients with DKD. The search for literature spanned over a period from 1966 to March 2006. Compared with placebo or usual care, PTX treatment for a median duration of 6 months decreased proteinuria in patients with DKD. Patients with overt proteinuria, as opposed to microalbuminuria, had a more significant decrease in urinary protein excretion after PTX treatment. No differences in proteinuria reduction between PTX and ACEIs, and no significant changes in systolic or diastolic blood pressure, or GFR were observed after PTX treatment. The authors suggested that large high-quality studies are required. This report was followed by a Cochrane systematic review which analyzed 17 studies comprising 991 participants with DKD as of 2009 [51]. The review claimed insufficient evidence to recommend the use of PTX for DKD and called for rigorously designed, randomized, multicenter, large-scale studies. A subsequent meta-analysis by Tian et al. [52], who analyzed 8 studies including 587 patients as of December 2014. The authors concluded that PTX therapy may additively reduce proteinuria, albuminuria and urinary TNF- $\alpha$ in DKD patients under RAS blockade. Of note, this beneficial effect was independent from the decrease in blood pressure or improvement in glycemic control. Likewise, Jiang et al. [53] analyzed 12 studies comprising 613 patients with CKD of various etiologies including DKD as of January 2015, and summarized that PTX decreased proteinuria compared to placebo or no-treatment groups, and the decrease was not significant compared to captopril treatment. Thus, 3 out of 4 (75\%) meta-analyses support the efficacy of PTX on reducing diabetic proteinuria.

\section{Efficacy of PTX on progression of CKD}

The renoprotective potential of PTX has been eagerly reviewed [10, 11, 54-56] or meta-analyzed $[57,58]$ in recent years. Most such analyses, however, were based on clinical trials with varied study designs and treatment protocols, yielding inconclusive results and hampering the recommendation of PTX to the whole CKD population (Table 3). In fact, due to the potent renoprotective effect of RAS blockade, and the insidious nature of renal progression, it may be hard to observe extra benefits of PTX on top of RAS blockade, especially in studies with short treatment duration. For that reason, only outcome analyses with an average follow-up period of at least 12 months are discussed in the following sections.

Lin et al. [47] first reported 56 patients (72\% being non-diabetic) with CKD stages 3 to 4 and urinary protein excretion $>0.5 \mathrm{~g} / \mathrm{gCr}$ in an open-label, randomized controlled trial. These patients had received ARB (losartan $100 \mathrm{mg}$ daily) for at least 6 months at entry, and were allocated to receive either ARB or add-on PTX (400 mg once or twice daily depending on eGFR levels) to ARB. At 1 year, the add-on group displayed a lower proteinuria than the ARB group. Further analysis revealed a significant decrease of eGFR in the ARB but not the add-on PTX group at 12 months. Mechanistically, add-on PTX therapy reduced changes in urinary TNF- $\alpha$ and MCP-1 as compared to the ARB group. The investigators then continued the follow-up of the add-on group and added PTX to the ARB group after 1 year. The results showed that PTX treatment not only persistently decreased proteinuria, but also reproduced this benefit of add-on PTX in the ARB group over an additional follow-up of 6 months. The use of add-on PTX in this trial was well-tolerated for patients over a follow-up period of 18 months. This was the first demonstration that PTX could reduce proteinuria on top of ARB in patients with stages 3 to 4 CKD.

Then, Navarro-González et al. [48] reported the PREDIAN trial, the largest open-label, randomized controlled study to date, which comprised 169 type 2 diabetics at CKD stages 3 to 4 with albuminuria $>30 \mathrm{mg} /$ day under maximal RAS blockade. After 24 months of treatment, a higher reduction of albuminuria and a lower decrease in the eGFR were observed in the PTX group. The authors concluded that add-on PTX (1200 mg daily) to RAS blockade in type 2 diabetics led to a smaller decrease in eGFR and a greater reduction of residual albuminuria at 2 years. These benefits were associated with decreased urinary TNF- $\alpha$ in the PTX group but not in the control. Despite promising results, $\mathrm{He} \&$ Cooper [59] pointed out several limitations in this study and suggested that 


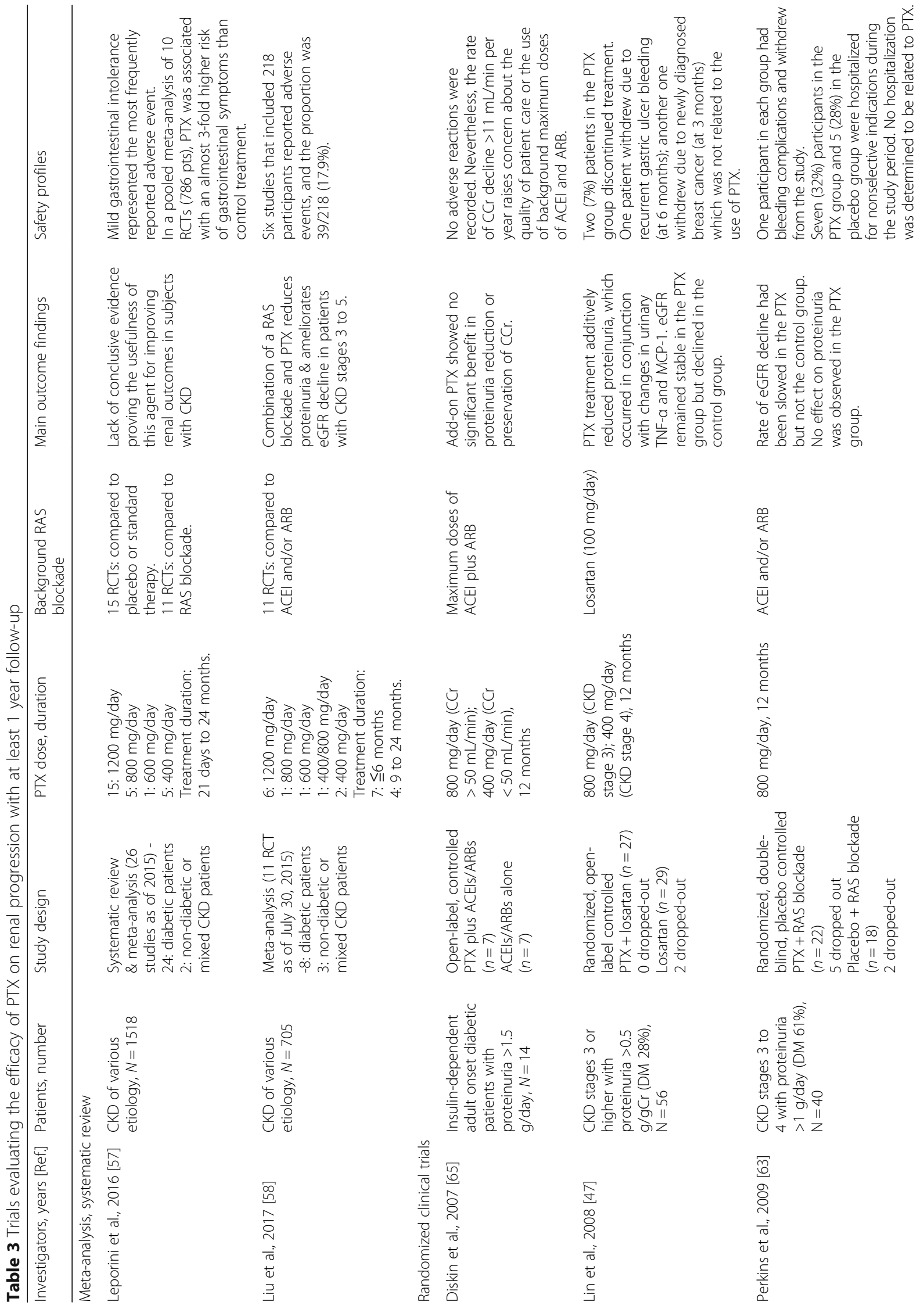




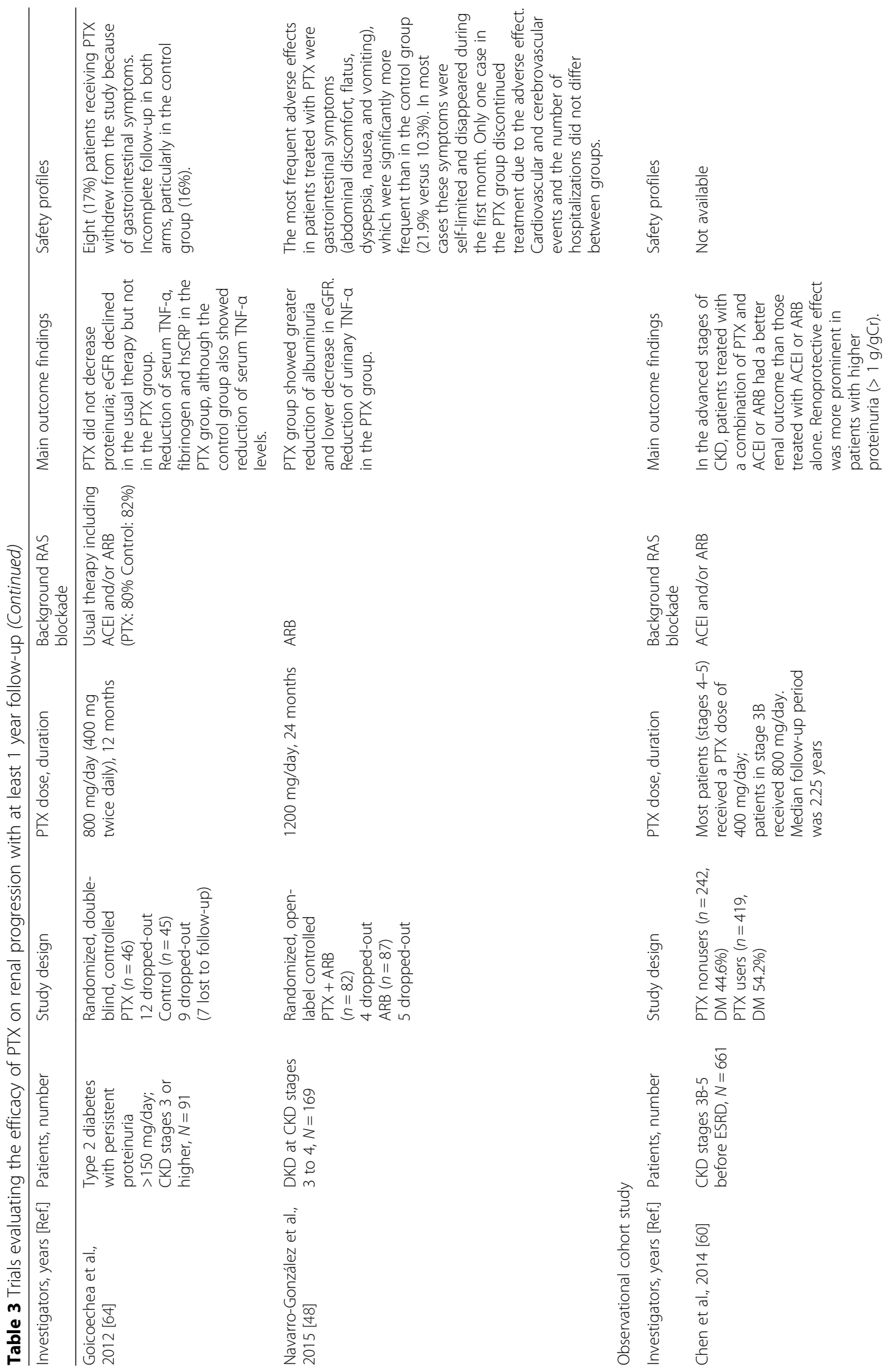




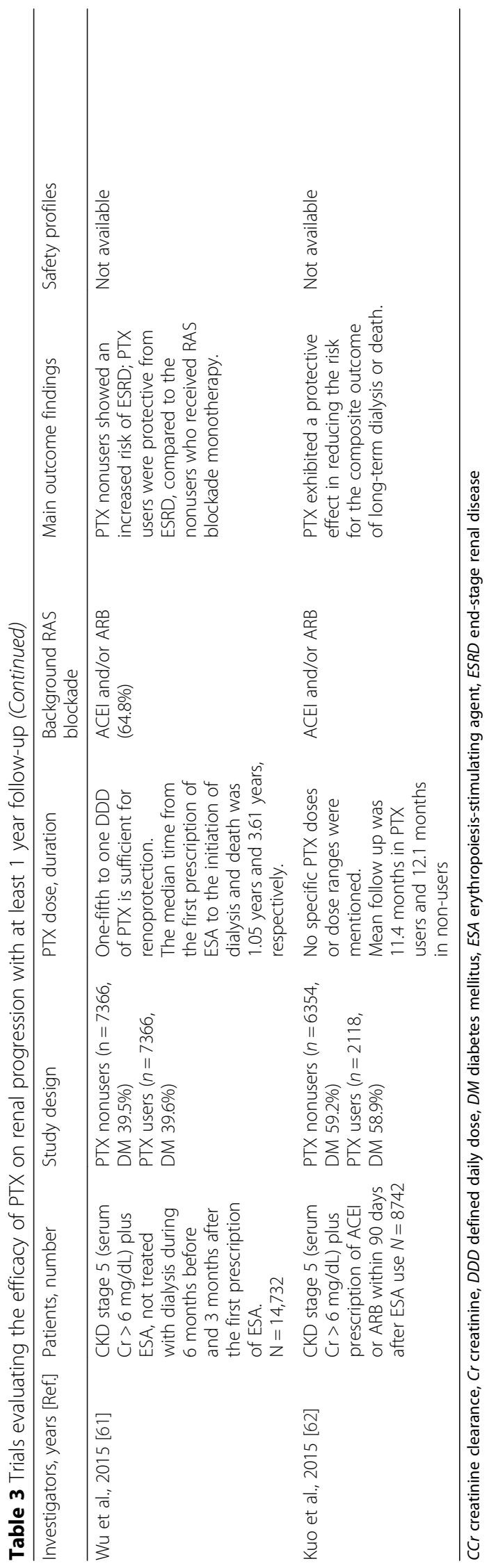


a large-scale, randomized, double-blind, adequately powered, placebo-controlled, multicenter trial be undertaken to provide further evidence of the potential renoprotective effects of PTX in a real-world setting.

Most prior studies had been conducted in patients with CKD across stages 1 to 4 and used proteinuria or eGFR decline rate as surrogate outcomes. Whether PTX may exhibit efficacy on hard renal endpoints such as ESRD or death in more advanced CKD remains relatively unexplored. Recently, Chen et al. [60] analyzed 609 patients with CKD stage 3B to 5 before ESRD in a single-center observational study and found that add-on PTX provided nephroprotection in the subset of patients with high proteinuria $(\geqq 1 \mathrm{~g} / \mathrm{gCr}$ ). This suggests that proteinuria may be a predictor of response to PTX at the individual patient level. Then, by analyzing a nationwide administrative dataset, Wu et al. [61] identified two propensity score-matched cohorts, PTX users and nonusers, each consisting of 7366 patients, from an original population of 23,233 individuals diagnosed as advanced CKD with a serum $\mathrm{Cr}>6 \mathrm{mg} / \mathrm{dL}$ and not treated with dialysis during 6 months before and 3 months after the first prescription of erythropoietinstimulating agent. The authors found that the PTX users were protective from ESRD, compared to the nonusers who received RAS blockade monotherapy. Importantly, this study showed that PTX as low as $200 \mathrm{mg}$ daily was sufficient to reduce the risk of new-onset ESRD in patients with advanced CKD, who often could not tolerate the use of RAS blockade. Likewise, by analyzing the same dataset of advanced CKD, Kuo et al. [62] reported that addition of PTX to background RAS blockade resulted in reduction of the risk for the composite outcome of long-term dialysis or death. Of note, the authors found no renal benefits by combining PTX with dual RAS blockade therapy compared with PTX and ARB monotherapy. Together, these cohort studies, albeit observational, provide first evidence that PTX can be an efficacious agent in reducing the risk of ESRD even in patients with late stage CKD.

Not all studies have shown concomitant anti-proteinuric and renoprotective effects by adding PTX to RAS blockade. In a double-blind, randomized, placebo-controlled design, Perkins et al. [63] examined add-on PTX (800 mg daily) to RAS blockade in 40 patients ( $61 \%$ being diabetic) with CKD stages 3 to 4 exhibiting proteinuria $>1$ g/day. At 1 year, the mean eGFR decrease was significantly less in the PTX group than the placebo group. And, for PTX-treated participants, the mean eGFR decrease during treatment was slower compared with the year before study enrollment. However, the authors did not observe PTX decreased proteinuria in comparison with the control group. They speculated that PTX might exert a greater action on tubulointerstitial injury than on glomerular filtration, and proposed that proteinuria may not always serve as an optimal surrogate outcome in studies evaluating the impact of
PTX on kidney function. This study comprised a greater percentage of African Americans and patients with diabetes in the PTX group, and displayed an unusually high rates of hospitalization (28-32\%) and dropped-out (17.5\%), which could underestimate the anti-proteinuric potential of PTX. Later, in another open-label, randomized controlled trial, Goicoechea et al. [64] reported PTX therapy at a dose of $800 \mathrm{mg}$ daily for 1 year stabilized renal function while decreasing serum inflammatory markers (TNF- $\alpha$, fibrinogen and high sensitivity CRP) in 91 patients with CKD stage 3 or higher. The study, which also did not find antiproteinuric effect of PTX in comparison to control, was limited by a high dropped-out rate $(17 \%)$ in the PTX group, and incomplete follow-up in both arms, particularly the control (16\%). Finally, Diskin et al. [65] reported 14 adult-onset, insulin-dependent diabetic patients with nephrotic proteinuria in an open-label, controlled trial. At 1 year, the authors did not find additive anti-proteinuric or renoprotective effects of PTX at a dose of $400-800 \mathrm{mg}$ daily on background ACEIs plus ARBs. These unexpected results could be related to the nature of the study which was small and non-randomized, and the rate of creatinine clearance decline was abnormally high $(>11 \mathrm{~mL} / \mathrm{min}$ per year), thus raising questions about the overall quality of the trial, and the safety of dual RAS blockade $[66,67]$.

\section{Possible mechanisms underlying PTX's renal effects}

Modulation of intracellular cyclic nucleotides by targeting PDE activity can be a novel therapeutic strategy for fibrotic kidney disease [68-70]. Currently, there are 11 PDE families with $>60$ isoforms which control the degradation of cyclic adenosine-3,5-monophosphate (cAMP) and cyclic guanosine-3,5-monophosphate (cGMP) within all mammalian cells [71-74]. Figure 1 illustrates the mechanisms underlying PTX's renoprotective activities. Initially, PTX suppresses distinct cAMP PDE isozymes and elevates intracellular cAMP [75]. This results in activation of protein kinase A (PKA) activity which leads to phosphorylation of downstream effectors followed by inhibition of signaling pathways involved in proteinuria and renal fibrosis [41, 76-78]. Along this line of thought, inhibition of type 3 and type 4 PDE isozymes has been shown to suppress mitogenesis of mesangial cells and development of mesangial proliferative glomerulonephritis in rats $[79,80]$. Our in vitro studies have shown that PTX acts through PKA-dependent pathway to inhibit type 3 and/or type 4 PDE isozymes, leading to elevated cAMP but not cGMP levels [76, 77, 81]. In vivo, PTX attenuates proteinuria and renal pathologies in several non-diabetic kidney disease models via modulation of signaling pathways or components triggered by cytokines (TNF- $\alpha$, nuclear factor- $\mathrm{kB}$, intercellular adhesion molecule-1, MCP-1 and CX3CL1/fractalkine), mitogens (platelet-derived growth factor, mitogen-activated protein kinase, phosphatidylinositol 


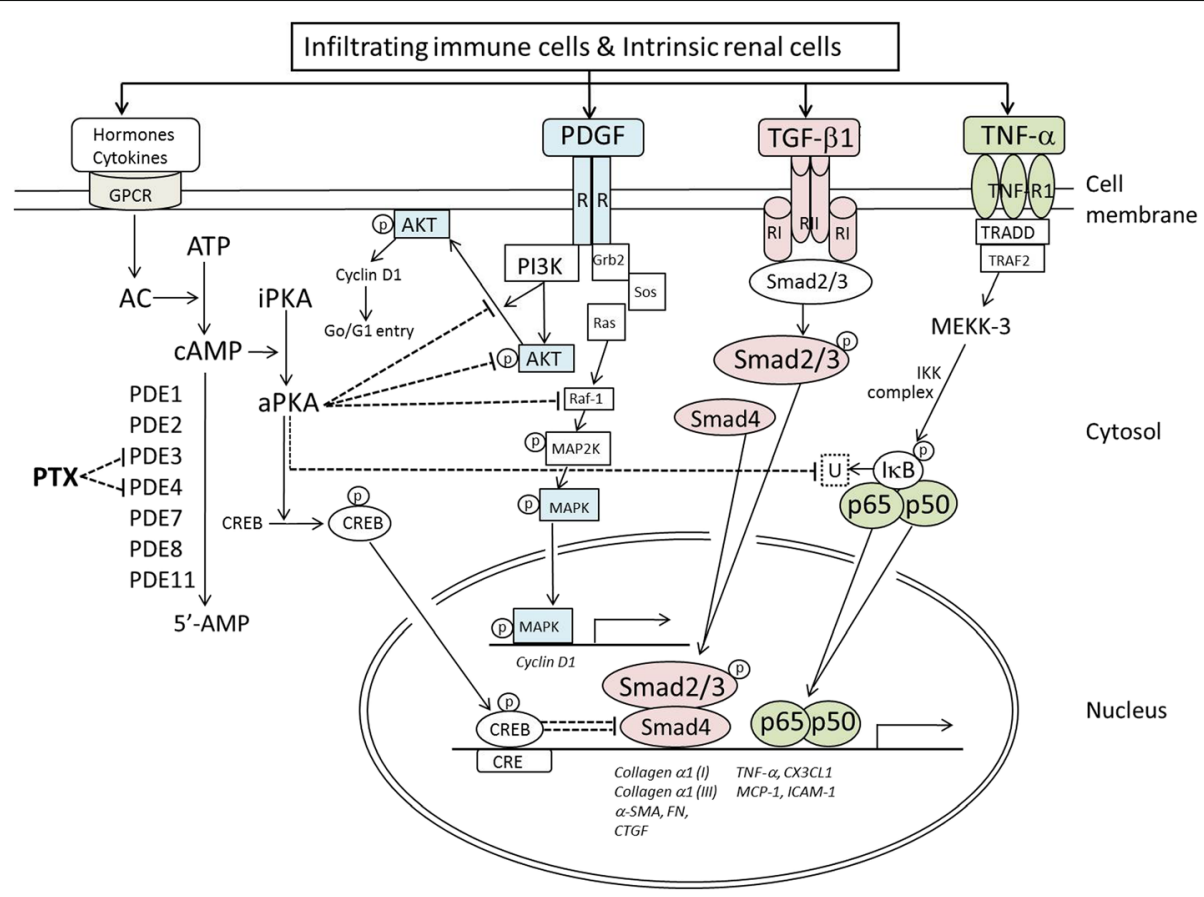

Fig. 1 Possible mechanisms mediating PTX's renal effects. AC, adenylate cyclase; aPKA, active protein kinase A; a-SMA, a-smooth muscle actin; ATP, adenosine triphosphate; CAMP, cyclic adenosine-3,5-monophosphate; CRE, CAMP response element; CREB, CAMP-response element binding protein; CTGF, connective tissue growth factor; CX3CL1, fractalkine; FN, fibronectin; GPCP, G-protein-coupled receptor; Grb2, growth factor receptorbound protein 2; ICAM-1, intercellular adhesion molecule-1; IKB, inhibitory protein of NF-KB (p65/p50 heterodimer); IKK, IKB kinase; iPKA, inactive protein kinase A; MAPK, mitogen activated protein kinase; MCP-1, monocyte chemoattractant protein-1; P, phosphorylation; PDE, phosphodiesterase; PDGF, platelet-derived growth factor; PI3K, phosphatidylinositol 3-kinase; Sos, son of sevenless; TGF- $\beta 1$, transforming growth factor- $\beta 1$; TNF-a, tumor necrosis factor-a; PTX, pentoxifylline; TRADD, TNFR1-associated death domain protein; TRAF2, TNF receptor-associated factor 2; U, ubiquitination. Dash lines denote inhibitory pathways initiated by PTX from the leftmost side

3-kinase, Akt/protein kinase B and cyclin D1) and fibrogenic molecules (transforming growth factor- $\beta$, Smad3/4, connective tissue growth factor, collagen types $1 \& 3$, fibronectin and $\alpha$-smooth muscle actin) [37, 78, 82-84]. In DKD models, PTX ameliorates sodium retention and renal hypertrophy together with reduced renal TNF production [85], and decrease albuminuria along with reduction of renal TNF- $\alpha$, interleukin (IL)-1 and IL-6 [86]. In a subsequent report, PTX exhibits its anti-inflammatory and antioxidant activities via decreasing the expression of TNF- $\alpha$ and IL-6 in alloxan-induced diabetes [87]. These data indicate that PTX's renal effects may be mediated via attenuation of proinflammatory cytokine cascades, irrespective of diabetes status.

It has been reported that TNF- $\alpha$ downregulate nephrin expression and cAMP-elevating agents enhance nephrin level in cultured podocytes [88]. More recently, in a mesangial proliferative glomerulonephritic model, Chen et al. [89] demonstrate that PTX can attenuate proteinuria and nephrinuria in conjunction with downregulation of the p-nuclear factor- $\mathrm{k} B$ and $\mathrm{p}$-Smad2/3 signaling pathways, and restoration of the decreased expression for the podocyte glomerular filtration barrier, including Wilms' tumor 1 , nephrin, synaptopodin and podocin. These seemingly non- specific actions of PTX may turn out to be an advantage and form the basis of developing new drugs with pleiotropic activities beyond RAS blockade. Recently, a novel small molecule drug, CTP-499, which mimics the primary metabolites of PTX has demonstrated its safety and tolerability in a phase $1 \mathrm{~b}$ randomized, double-blind, placebo controlled clinical trial in patients with CKD [90].

Apart from blocking the PDE activity, PTX can modulate other effectors or signaling pathways depending on the experimental settings. In vitro, PTX suppresses TNF- $\alpha$ production via PKA-independent pathway in endotoxinactivated mononuclear cells [91], and inhibits tumor growth and angiogenesis by targeting Janus kinase-signal transducer and activator of transcription signaling [92]. In vivo, PTX attenuates endotoxin-induced acute lung injury via adenosine receptor $\mathrm{A}_{2 \mathrm{~A}}$-dependent cascade [93], and ameliorates alloxan-induced diabetes by reduction of inducible nitric oxide synthase system [87]. Whether these TNF- $\alpha$ independent mechanisms play a role in mediating PTX's effects still awaits further studies.

\section{Safety profile of PTX use in patients with kidney disease} The most common adverse effects of PTX are gastrointestinal symptoms and dizziness [15, 52, 94]. Presumably, 
these effects of PTX may occur more frequently in patients whose dosages are not tailored by degrees of renal dysfunction. For instances, Renke et al. [25] observed a relatively high incidence of adverse effects, i.e., nausea, dyspepsia and diarrhea in 5 patients (23\%) during the study period. They considered this could be ascribed to no reduction of PTX doses in patients with moderate renal dysfunction, which resulted in accumulation of PTX metabolites and gastrointestinal intolerance. Also in the PREDIAN trial [48], the incidence of abdominal discomfort, flatus, dyspepsia, nausea, and vomiting in patients treated with PTX was significantly higher than in the control group (21.9\% versus $10.3 \%)$. That said, these digestive symptoms were generally self-limited and usually disappeared when used continuously with proper dose adjustment beyond the first month. During multidose pharmacokinetic studies, accumulation of active metabolites IV and V has been documented in patients with renal impairment. For that reason, dose reduction to $400 \mathrm{mg}$ twice daily and $200-400 \mathrm{mg}$ daily is advised for patients with creatinine clearances between 30 and 80 , and $<30 \mathrm{~mL} / \mathrm{min}$, respectively $[95,96]$.

There exists concern that PTX might exert a negative impact on glycemic control in patients with diabetes. Previous studies have shown that PDE3,4 inhibitors enhance both glycogenolysis and gluconeogenesis in hepatocytes isolated from fasted rats [97], and the blood glucose level increases following the administration of cilostazol, a PDE3 inhibitor, in three patients with type 2 diabetes [98]. More recently, however, PDE4 inhibitors have been shown to improve glucose homeostasis in diabetic mice [99] and human patients [100], likely via enhancing the secretion of cAMP-mediated glucagon-like peptide 1 [99]. Further, of all the literatures reviewed (Tables 1,2,3), there was no report that PTX increased blood glucose in diabetic patients with overt proteinuria or CKD of various stages. In a meta-analysis of 499 patients with type 2 diabetic nephropathy from 6 clinical trials, Tian et al. [52] observed no significant change of HbA1c in the PTX group compared with that of the control. On top of that, Han et al. [46] reported that add-on PTX reduced proteinuria in conjunction with improved glucose control and insulin resistance in patients with type 2 diabetes.

\section{Conclusions}

PTX is a nonselective PDE inhibitor that exhibits antiinflammatory, anti-proliferative and anti-fibrotic actions both in vitro and in vivo. Current evidence suggests that PTX, used either alone or in combination with RAS blockade, may have an adjunct role of renoprotection for CKD. Nevertheless, most published literatures were limited by small sample size, short observation period and imperfect methodology using surrogate outcomes (proteinuria, eGFR decline). There is need for more well-designed studies with longer duration of follow-up aiming at hard renal endpoints (ESRD, doubling of serum creatinine). Because PTX is an old drug that lacks financial sponsorship, future researches examining the efficacy PTX on a background of RAS blockade would better be conducted on patients with more severe $\mathrm{CKD}$, e.g., stage $3 \mathrm{~B}$ or higher, so that hard outcomes can be evaluated using a minimum number of subjects within an acceptable period of time.

\section{Abbreviations \\ ACEl: Angiotensin converting enzyme inhibitor; ARB: Angiotensin receptor blockers; CAMP: Cyclic adenosine-3,5-monophosphate; cGMP: Cyclic guanosine- 3,5-monophosphate; CKD: Chronic kidney disease; CRP: C-reactive protein: DKD: Diabetic kidney disease; eGFR: Estimated glomerular filtration rate; ESRD: End-stage renal disease; IL: Interleukin; MCP: Monocyte chemoattractant protein; PDE: Phosphodiesterase; PKA: Protein kinase A; PTX: Pentoxifylline: RAS: Renin-angiotensin system; TNF: Tumor necrosis factor}

\section{Acknowledgements}

We thank Dr. Tai-Shuan Lai for helping the collection of relevant literature.

\section{Funding}

This study was supported by grants from the Ministry of Science and Technology (100-2314-B-002-067-MY2, 101-2314-B-002-084-MY3, 105-2314-B-002-096-MY3), the National Taiwan University Hospital (105-003126), Ta-Tung Kidney Foundation and the Mrs. Hsiu-Chin Lee Kidney Research Fund, Taipei, Taiwan.

\section{Availability of data and materials \\ Not applicable.}

\section{Authors' contributions}

YMC and SLL are equally contributed and wrote the first draft of this review. WCC and TJT contributed additional materials and made revisions. All authors read and approved the final manuscript.

Ethics approval and consent to participate

Not applicable.

Consent for publication

None.

\section{Competing interests}

The authors declare that they have no competing interests.

\section{Publisher's Note}

Springer Nature remains neutral with regard to jurisdictional claims in published maps and institutional affiliations.

\section{Author details}

${ }^{1}$ Renal Division, Department of Medicine, National Taiwan University Hospital, College of Medicine, National Taiwan University, No. 7, Chung-Shan South Road, Taipei, Taiwan. ${ }^{2}$ Graduate Institute of Physiology, College of Medicine, National Taiwan University, No. 1, Jen-Ai Road, Section 1, Taipei, Taiwan.

Received: 25 July 2017 Accepted: 30 October 2017

Published online: 13 November 2017

\section{References}

1. Kidney Disease. Improving global outcomes (KDIGO) blood pressure work group. KDIGO clinical practice guideline for the management of blood pressure in chronic kidney disease. Kidney inter, Suppl. 2012;2:337-414.

2. Kidney Disease. Improving global outcomes (KDIGO) CKD work group. KDIGO 2012 clinical practice guideline for the evaluation and management of chronic kidney disease. Kidney inter., Suppl. 2013;3:1-150.

3. Taiwan chronic kidney clinical guidelines 2015. http://www.tsn.org.tw/Ul/H/ H00202.aspx [Article in Chinese]. 
4. Remuzzi G, Benigni A, Remuzzi A. Mechanisms of progression and regression of renal lesions of chronic nephropathies and diabetes. J Clin Invest. 2006;116:288-96.

5. Usuelli V, La Rocca E. Novel therapeutic approaches for diabetic nephropathy and retinopathy. Pharmacol Res. 2015;98:39-44.

6. Wanner C, Inzucchi SE, Lachin JM, Fitchett D, von Eynatten M, Mattheus M, Johansen OE, Woerle HJ, Broedl UC, Zinman B, EMPA-REG OUTCOME Investigators. Empagliflozin and progression of kidney disease in type 2 diabetes. N Engl J Med. 2016;375:323-34.

7. Fernandez-Fernandez B, Ortiz A, Gomez-Guerrero C, Egido J. Therapeutic approaches to diabetic nephropathy - beyond the RAS. Nat Rev Nephrol. 2014;10:325-46.

8. Maas RJ, Wetzels JF. Glomerular disease in 2016: new advances in the treatment of glomerular disease. Nat Rev Nephrol. 2017;13:65-6.

9. Lee SY, Kim SI, Choi ME. Therapeutic targets for treating fibrotic kidney diseases. Transl Res. 2015;165:512-30.

10. Toth-Manikowski S, Atta MG. Diabetic kidney disease: pathophysiology and therapeutic targets. J Diabetes Res. 2015;2015:697010.

11. Carson C, Al-Makki A, Shepler B. Can pentoxifylline be used as adjunct therapy to ACE inhibitors and ARBs in preserving kidney function? J Pharm Pharm Sci. 2016:19:1-7.

12. McCarty MF, O'Keefe JH, DiNicolantonio JJ. Pentoxifylline for vascular health: a brief review of the literature. Open Heart. 2016;3:e000365.

13. Jacoby D, Mohler ER III. Drug treatment of intermittent claudication. Drugs. 2004:64:1657-70.

14. Müller R. Pentoxifylline - a biomedical profile. J Med. 1979;10:307-29.

15. Ward A, Clissold SP. Pentoxifylline. A review of its pharmacodynamic and pharmacokinetic properties, and its therapeutic efficacy. Drugs. 1987;34:50-97.

16. Zhang M, YJ X, Mengi SA, Arneja AS, Dhalla NS. Therapeutic potentials of pentoxifylline for treatment of cardiovascular diseases. Exp Clin Cardiol. 2004:9:103-11.

17. Rajendran R, Rani V, Shaikh S. Pentoxifylline therapy: a new adjunct in the treatment of oral submucous fibrosis. Indian J Dent Res. 2006;17:190-8.

18. Nasiri-Toosi Z, Dashti-Khavidaki S, Khalili H, Lessan-Pezeshki M. A review of the potential protective effects of pentoxifylline against drug-induced nephrotoxicity. Eur J Clin Pharmacol. 2013;69:1057-73.

19. Fan H, Kim SM, Cho YJ, Eo MY, Lee SK, Woo KM. New approach for the treatment of osteoradionecrosis with pentoxifylline and tocopherol. Biomater Res. 2014;18:13.

20. Hassan I, Dorjay K, Anwar P. Pentoxifylline and its applications in dermatology. Indian Dermatol Online J. 2014;5:510-6.

21. Thursz MR, Richardson P, Allison M, Austin A, Bowers M, Day CP, Downs N, Gleeson D, MacGilchrist A, Grant A, Hood S, Masson S, McCune A, Mellor J, O'Grady J, Patch D, Ratcliffe I, Roderick P, Stanton L, Vergis N, Wright M, Ryder S, Forrest EH, STOPAH Trial. Prednisolone or pentoxifylline for alcoholic hepatitis. N Engl J Med. 2015;372:1619-28.

22. Lin SL, Chen YM, Chiang WC, Tsai TJ, Chen WY. Pentoxifylline: a potential therapy for chronic kidney disease. Nephrology (Carlton). 2004;9:198-204.

23. Lin SL, Chiang WC, Chen YM, Lai CF, Tsai TJ, Hsieh BS. The renoprotective potential of pentoxifylline in chronic kidney disease. J Chin Med Assoc. 2005;68:99-105.

24. Chen YM, Lin SL, Chiang WC, Wu KD, Tsai TJ. Pentoxifylline ameliorates proteinuria through suppression of renal monocyte chemoattractant protein-1 in patients with proteinuric primary glomerular diseases. Kidney Int. 2006;69:1410-5.

25. Renke M, Tylicki L, Rutkowski P, Knap N, Zietkiewicz M, Neuwelt A, Aleksandrowicz E, Łysiak-Szydłowska W, Woźniak M, Rutkowski B. Effect of pentoxifylline on proteinuria, markers of tubular injury and oxidative stress in non-diabetic patients with chronic kidney disease - placebo controlled, randomized, cross-over study. Acta Biochim Pol. 2010;57:119-23.

26. Badri S, Dashti-Khavidaki S, Ahmadi F, Mahdavi-Mazdeh M, Abbasi MR, Khalili H. Effect of add-on pentoxifylline on proteinuria in membranous glomerulonephritis: a 6-month placebo-controlled trial. Clin Drug Investig. 2013:33:215-22.

27. Noel C, Hazzan M, Labalette M, Coppin MC, Jude B, Dessaint JP, Lelievre G. Improvement in the outcome of rejection with pentoxifylline in renal transplantation: a randomized controlled trial. Transplantation. 1998;65:385-9.

28. Shu KH, MJ W, Chen $\mathrm{CH}$, Cheng $\mathrm{CH}$, Lian JD, Lu YS. Effect of pentoxifylline on graft function of renal transplant recipients complicated with chronic allograft nephropathy. Clin Nephrol. 2007;67:157-63.

29. Hamidian Jahromi A, Kessaris N, Sharifian M, Roozbeh J. Protective effect of pentoxifylline in the kidney perfusion fluid on the transplanted kidney. Saudi J Kidney Dis Transpl. 2009;20:290-1.
30. Saran R, Robinson B, Abbott KC, et al. US renal data system 2016 annual data report: epidemiology of kidney disease in the United States. Am J Kidney Dis. 2017;69(suppl 1):S1-S688.

31. Cao Z, Cooper ME. Pathogenesis of diabetic nephropathy. J Diabetes Investig. 2011;2:243-7.

32. Gnudi L, Coward RJ, Long DA. Diabetic nephropathy: perspective on novel molecular mechanisms. Trends Endocrinol Metab. 2016;27:820-30.

33. Navarro-González JF, Mora-Fernández C. The role of inflammatory cytokines in diabetic nephropathy. J Am Soc Nephrol. 2008;19:433-42.

34. Shikata K, Makino H. Microinflammation in the pathogenesis of diabetic nephropathy. J Diabetes Investig. 2013;4:142-9.

35. Donate-Correa J, Martín-Núñez E, Muros-de-Fuentes M, Mora-Fernández C, Navarro-González JF. Inflammatory cytokines in diabetic nephropathy. J Diabetes Res. 2015;2015:948417.

36. Usta Y, Ismailoglu UB, Bakkaloglu A, Orhan D, Besbas N, Sahin-Erdemli I, Ozen S. Effects of pentoxifylline in adriamycin-induced renal disease in rats. Pediatr Nephrol. 2004;19:840-3.

37. Chen YM, Ng YY, Lin SL, Chiang WC, Lan HY, Tsai TJ. Pentoxifylline suppresses renal tumor necrosis factor-alpha and ameliorates experimental crescentic glomerulonephritis in rats. Nephrol Dial Transplant. 2004;19:1106-15.

38. Rodríguez-Morán M, Guerrero-Romero F. Efficacy of pentoxifylline in the management of microalbuminuria in patients with diabetes. Curr Diabetes Rev. 2008:4:55-62.

39. Aminorroaya A, Janghorbani $M$, Rezvanian $H$, Aminian $T$, Gharavi M, Amini M. Comparison of the effect of pentoxifylline and captopril on proteinuria in patients with type 2 diabetes mellitus. Nephron Clin Pract. 2005;99:C73-7.

40. Rodríguez-Morán M, Guerrero-Romero F. Pentoxifylline is as effective as captopril in the reduction of microalbuminuria in non-hypertensive type 2 diabetic patients-a randomized, equivalent trial. Clin Nephrol. 2005;64:91-7.

41. Navarro JF, Mora C, Muros M, García J. Additive antiproteinuric effect of pentoxifylline in patients with type 2 diabetes under angiotensin II receptor blockade: a short-term, randomized, controlled trial. J Am Soc Nephrol. 2005;16:2119-26.

42. Rodriguez-Morán M, González-González G, Bermúdez-Barba MV, Medina de la Garza CE, Tamez-Pérez HE, Martínez-Martínez FJ, Guerrero-Romero F. Effects of pentoxifylline on the urinary protein excretion profile of type 2 diabetic patients with microproteinuria: a double-blind, placebo-controlled randomized trial. Clin Nephrol. 2006:66:3-10.

43. Oliaei F, Hushmand S, Khafri S, Baradaran M. Efficacy of pentoxifylline for reduction of proteinuria in type II diabetic patients. Caspian J Intern Med. 2011;2:309-13.

44. Ghorbani A, Omidvar B, Beladi-Mousavi SS, Lak E, Vaziri S. The effect of pentoxifylline on reduction of proteinuria among patients with type 2 diabetes under blockade of angiotensin system: a double blind and randomized clinical trial. Nefrologia. 2012;32:790-6.

45. Roozbeh J, Banihashemi MA, Ghezlou M, Afshariani R, Salari S, Moini M, Sagheb MM. Captopril and combination therapy of captopril and pentoxifylline in reducing proteinuria in diabetic nephropathy. Ren Fail. 2010;32:172-8.

46. Han SJ, Kim HJ, Kim DJ, Sheen SS, Chung CH, Ahn CW, Kim SH, Cho YW, Park SW, Kim SK, Kim CS, Kim KW, Lee KW. Effects of pentoxifylline on proteinuria and glucose control in patients with type 2 diabetes: a prospective randomized double-blind multicenter study. Diabetol Metab Syndr. 2015;7:64

47. Lin SL, Chen YM, Chiang WC, Wu KD, Tsai TJ. Effect of pentoxifylline in addition to losartan on proteinuria and GFR in CKD: a 12-month randomized trial. Am J Kidney Dis. 2008;52:464-74.

48. Navarro-González JF, Mora-Fernández C, Muros de Fuentes M, Chahin J, Méndez ML, Gallego E, Macía M, del Castillo N, Rivero A, Getino MA, García $P$, Jarque A, García J. Effect of pentoxifylline on renal function and urinary albumin excretion in patients with diabetic kidney disease: the PREDIAN trial. J Am Soc Nephrol. 2015;26:220-9.

49. Shahidi S, Hoseinbalam M, Iraj B, Akbari M. Effect of pentoxifylline on microalbuminuria in diabetic patients: a randomized controlled trial. Int J Nephrol. 2015:2015:259592.

50. McCormick BB, Sydor A, Akbari A, Fergusson D, Doucette S, Knoll G. The effect of pentoxifylline on proteinuria in diabetic kidney disease: a metaanalysis. Am J Kidney Dis. 2008;52:454-63.

51. Shan D, Wu HM, Yuan QY, Li J, Zhou RL, Liu GJ. Pentoxifylline for diabetic kidney disease. Cochrane Database Syst Rev. 2012;2:CD006800.

52. Tian ML, Shen $Y$, Sun ZL, Zha Y. Efficacy and safety of combining pentoxifylline with angiotensin-converting enzyme inhibitor or angiotensin II receptor 
blocker in diabetic nephropathy: a meta-analysis. Int Urol Nephrol. 2015;47: $815-22$.

53. Jiang X, Zhou S, Yao J, Kong X, Cui M. Effect of pentoxifylline in proteinuric chronic kidney disease: a systematic review and meta-analysis. J Nephrol. 2016;29:653-62.

54. Badri S, Dashti-Khavidaki S, Lessan-Pezeshki M, Abdollahi M. A review of the potential benefits of pentoxifylline in diabetic and non-diabetic proteinuria. J Pharm Pharm Sci. 2011;14:128-37.

55. Bhanot S, Leehey DJ. Pentoxifylline for diabetic nephropathy: an important opportunity to re-purpose an old drug? Curr Hypertens Rep. 2016;18:8.

56. Lai TS, Chiang WC, Chen YM. Pentoxifylline: evidence strong enough for renoprotection? J Formos Med Assoc. 2016;115:591-2.

57. Leporini C, Pisano A, Russo E, D'Arrigo G, de Sarro G, Coppolino G, Bolignano D. Effect of pentoxifylline on renal outcomes in chronic kidney disease patients: a systematic review and meta-analysis. Pharmacol Res. 2016;107:315-32.

58. Liu D, Wang LN, Li HX, Huang P, Qu LB, Chen FY. Pentoxifylline plus ACEls/ ARBs for proteinuria and kidney function in chronic kidney disease: a metaanalysis. J Int Med Res. 2017;45:383-98.

59. He T, Cooper ME. Diabetic nephropathy: renoprotective effects of pentoxifylline in the PREDIAN trial. Nat Rev Nephrol. 2014;10:547-8.

60. Chen PM, Lai TS, Chen PY, Lai CF, Wu V, Chiang WC, Chen YM, KD W, Tsai TJ. Renoprotective effect of combining pentoxifylline with angiotensinconverting enzyme inhibitor or angiotensin II receptor blocker in advanced chronic kidney disease. J Formos Med Assoc. 2014;113:219-26.

61. PC W, CJ W, Lin CJ, Pan CF, Chen CY, Huang TM, CH W, Lin SL, Chen YM, Chen L, VCW, NSARF Group. Kidney consortium. Pentoxifylline decreases dialysis risk in patients with advanced chronic kidney disease. Clin Pharmacol Ther. 2015:98:442-9.

62. Kuo KL, Hung SC, Liu JS, Chang YK, Hsu CC, Tarng DC. Add-on protective effect of pentoxifylline in advanced chronic kidney disease treated with renin-angiotensin-aldosterone system blockade - a nationwide database analysis. Sci Rep. 2015;5:17150.

63. Perkins RM, Aboudara MC, Uy AL, Olson SW, Cushner HM, Yuan CM. Effect of pentoxifylline on GFR decline in CKD: a pilot, double-blind, randomized, placebo-controlled trial. Am J Kidney Dis. 2009;53:606-16.

64. Goicoechea M, García de Vinuesa S, Quiroga B, Verdalles U, Barraca D, Yuste C, Panizo N, Verde E, Muñoz MA, Luño J. Effects of pentoxifylline on inflammatory parameters in chronic kidney disease patients: a randomized trial. J Nephrol. 2012;25:969-75.

65. Diskin CJ, Stokes TJ, Dansby LM, Radcliff L, Carter TB. Will the addition of pentoxifylline reduce proteinuria in patients with diabetic glomerulosclerosis refractory to maximal doses of both an angiotensinconverting enzyme inhibitor and an angiotensin receptor blocker? J Nephrol. 2007;20:410-6.

66. Pichler RH, de Boer IH. Dual renin-angiotensin-aldosterone system blockade for diabetic kidney disease. Curr Diab Rep. 2010;10:297-305.

67. Gentile G, Remuzzi G, Ruggenenti P. Dual renin-angiotensin system blockade for nephroprotection: still under scrutiny. Nephron. 2015;129:39-41.

68. Keravis T, Lugnier C. Cyclic nucleotide phosphodiesterase (PDE) isozymes as targets of the intracellular signalling network: benefits of PDE inhibitors in various diseases and perspectives for future therapeutic developments. Br J Pharmacol. 2012:165:1288-305.

69. Maurice DH, Ke H, Ahmad F, Wang Y, Chung J, Manganiello VC. Advances in targeting cyclic nucleotide phosphodiesterases. Nat Rev Drug Discov. 2014; 13:290-314.

70. Schinner E, Wetzl V, Schlossmann J. Cyclic nucleotide signalling in kidney fibrosis. Int J Mol Sci. 2015;16:2320-51.

71. Torphy TJ. Phosphodiesterase isozymes: molecular targets for novel antiasthma agents. Am J Respir Crit Care Med. 1998;157:351-70.

72. Lugnier C. Cyclic nucleotide phosphodiesterase (PDE) superfamily: a new target for the development of specific therapeutic agents. Pharmacol Ther. 2006;109:366-98.

73. Cheng J, Grande JP. Cyclic nucleotide phosphodiesterase (PDE) inhibitors: novel therapeutic agents for progressive renal disease. Exp Biol Med (Maywood). 2007;232:38-51.

74. Adderley SP, Sprague RS, Stephenson AH, Hanson MS. Regulation of CAMP by phosphodiesterases in erythrocytes. Pharmacol Rep. 2010;62:475-82.

75. Windmeier C, Gressner AM. Pharmacological aspects of pentoxifylline with emphasis on its inhibitory actions on hepatic fibrogenesis. Gen Pharmacol. 1997;29:181-96.
76. Lin SL, Chen RH, Chen YM, Chiang WC, Tsai TJ, Hsieh BS. Pentoxifylline inhibits platelet-derived growth factor-stimulated cyclin D1 expression in mesangial cells by blocking Akt membrane translocation. Mol Pharmacol. 2003:64:811-22.

77. Chen YM, Chiang WC, Lin SL, Wu KD, Tsai TJ, Hsieh BS. Dual regulation of tumor necrosis factor-alpha-induced CCL2/monocyte chemoattractant protein-1 expression in vascular smooth muscle cells by nuclear factorkappaB and activator protein-1: modulation by type III phosphodiesterase inhibition. J Pharmacol Exp Ther. 2004;309:978-86.

78. Lin SL, Chen RH, Chen YM, Chiang WC, Lai CF, KD W, Tsai TJ. Pentoxifylline attenuates tubulointerstitial fibrosis by blocking Smad3/4-activated transcription and profibrogenic effects of connective tissue growth factor. J Am Soc Nephrol. 2005;16:2702-13.

79. Matousovic K, Grande JP, Chini CCS, Chini EN, Dousa TP. Inhibitors of cyclic nucleotide phosphodiesterase isozymes type-III and type-IV suppress mitogenesis of rat mesangial cells. J Clin Invest. 1995;96:401-10.

80. Tsuboi Y, Shankland SJ, Grande JP, Walker HJ, Johnson RJ, Dousa TP. Suppression of mesangial proliferative glomerulonephritis development in rats by inhibitors of CAMP phosphodiesterase isozymes types III and IV. J Clin Invest. 1996;98:262-70.

81. Chen YM, KD W, Tsai TJ, Hsieh BS. Pentoxifylline inhibits PDGF-induced proliferation of and TGF-beta-stimulated collagen synthesis by vascular smooth muscle cells. J Mol Cell Cardiol. 1999;31:773-83.

82. Chen YM, Chien CT, Hu-Tsai MI, KD W, Tsai CC, MS W, Tsai TJ. Pentoxifylline attenuates experimental mesangial proliferative glomerulonephritis. Kidney Int. 1999;56:932-43.

83. Lin SL, Chen YM, Chien CT, Chiang WC, Tsai CC, Tsai TJ. Pentoxifylline attenuated the renal disease progression in rats with remnant kidney. J Am Soc Nephrol. 2002;13:2916-29.

84. Ng YY, Chen YM, Tsai TJ, Lan XR, Yang WC, Lan HY. Pentoxifylline inhibits transforming growth factor-beta signaling and renal fibrosis in experimental crescentic glomerulonephritis in rats. Am J Nephrol. 2009;29:43-53.

85. DiPetrillo K, Gesek FA. Pentoxifylline ameliorates renal tumor necrosis factor expression, sodium retention, and renal hypertrophy in diabetic rats. Am J Nephrol. 2004;24:352-9.

86. Navarro JF, Milena FJ, Mora C, León C, García J. Renal pro-inflammatory cytokine gene expression in diabetic nephropathy: effect of angiotensinconverting enzyme inhibition and pentoxifylline administration. Am 」 Nephrol. 2006;26:562-70.

87. Garcia FA, Rebouças JF, Balbino TQ, da Silva TG, de Carvalho-Júnior $\mathrm{CH}$, Cerqueira GS, Brito GA, Viana GS. Pentoxifylline reduces the inflammatory process in diabetic rats: relationship with decreases of pro-inflammatory cytokines and inducible nitric oxide synthase. J Inflamm (Lond). 2015;12:33.

88. Saito Y, Okamura M, Nakajima S, Hayakawa K, Huang T, Yao J, Kitamura M. Suppression of nephrin expression by TNF-alpha via interfering with the CAMP-retinoic acid receptor pathway. Am J Physiol Renal Physiol. 2010;298: F1436-44.

89. Chen YM, Chiang WC, Yang Y, Lai CF, KD W, Lin SL. Pentoxifylline attenuates proteinuria in anti-Thy1 glomerulonephritis via downregulation of nuclear factor-KB and Smad2/3 signaling. Mol Med. 2015;21:276-84.

90. Sabounjian L, Graham P, Wu L, Braman V, Cheng C, Liu J, Shipley J, Neutel J, Dao M. A first-in-patient, multicenter, double-blind, 2-arm, placebo-controlled, randomized safety and tolerability study of a novel oral drug candidate, CTP499, in chronic kidney disease. Clin Pharmacol Drug Dev. 2016;5:314-25.

91. Deree J, Martins JO, Melbostad H, Loomis WH, Coimbra R. Insights into the regulation of TNF-alpha production in human mononuclear cells: the effects of non-specific phosphodiesterase inhibition. Clinics (Sao Paulo). 2008;63:321-8.

92. Kamran MZ, Gude RP. Pentoxifylline inhibits melanoma tumor growth and angiogenesis by targeting STAT3 signaling pathway. Biomed Pharmacother. 2013;67:399-405.

93. Konrad FM, Neudeck G, Vollmer I, Ngamsri KC, Thiel M, Reutershan J. Protective effects of pentoxifylline in pulmonary inflammation are adenosine receptor A2A dependent. FASEB J. 2013;27:3524-35.

94. Pentoxifylline: adverse effects. (2015). In Micromedex (Columbia Basin College Library ed.) [Electronic version]. Greenwood Village, CO: Truven Health Analytics. Retrieved September 21, 2017, from http://www. micromedexsolutions.com/micromedex2/librarian/PFDefaultActionld/ evidencexpert.DolntegratedSearch\#

95. Beermann B, Ings R, Månsby J, Chamberlain J, McDonald A. Kinetics of intravenous and oral pentoxifylline in healthy subjects. Clin Pharmacol Ther. 1985;37:25-8. 
96. Paap CM, Simpson KS, Horton MW, Schaefer KL, Lassman HB, Sack MR. Multiple-dose pharmacokinetics of pentoxifylline and its metabolites during renal insufficiency. Ann Pharmacother. 1996;30:724-9.

97. Abdollahi M, Chan TS, Subrahmanyam V, O'Brien PJ. Effects of phosphodiesterase $3,4,5$ inhibitors on hepatocyte cAMP levels, glycogenolysis, gluconeogenesis and susceptibility to a mitochondrial toxin Mol Cell Biochem. 2003;252:205-11.

98. Aoki Y, Shimizu M, Watanabe N. The blood glucose level increased in parallel with the heart rate following cilostazol administration in three diabetic patients. Intern Med. 2014;53:859-63.

99. Vollert S, Kaessner N, Heuser A, Hanauer G, Dieckmann A, Knaack D, Kley HP, Beume R, Weiss-Haljiti C. The glucose-lowering effects of the PDE4 inhibitors roflumilast and roflumilast- $\mathrm{N}$-oxide in $\mathrm{db} / \mathrm{db}$ mice. Diabetologia. 2012;55:2779-88.

100. Wouters EF, Bredenbroker D, Teichmann P, Brose M, Rabe KF, Fabbri LM, Goke B. Effect of the phosphodiesterase 4 inhibitor roflumilast on glucose metabolism in patients with treatment-naive, newly diagnosed type 2 diabetes mellitus. J Clin Endocrinol Metab. 2012;97:E1720-5.

Submit your next manuscript to BioMed Central and we will help you at every step:

- We accept pre-submission inquiries

- Our selector tool helps you to find the most relevant journal

- We provide round the clock customer support

- Convenient online submission

- Thorough peer review

- Inclusion in PubMed and all major indexing services

- Maximum visibility for your research

Submit your manuscript at www.biomedcentral.com/submit
Biomed Central 